$$
2
$$


Hommage Aux 12 apotres

Óleo sobre lienzo

$120 \times 120 \mathrm{cms}$

2009

Colección Privada

Universidad Santo Tomás 


\title{
LA RESPONSABILIDAD INTERNACIONAL DEL ESTADO COLOMBIANO EN LA JURISPRUDENCIA DE LA CORTE INTERAMERICANA DE DERECHOS HUMANOS
}

\author{
Óscar Mauricio Reina García \\ Abogado, Universidad Santo Tomás-Seccional Bucaramanga (Col); Especialista en Derecho \\ Administrativo, Universidad Externado de Colombia; Máster en Derecho Público, Universidad Carlos \\ III de Madrid, España. E-mail:mauricioreinag@hotmail.com
}

\begin{abstract}
Resumen
La constante violación de los derechos humanos ocasionada por el conflicto armado interno en el Estado colombiano, ha generado una serie de reclamaciones de las víctimas, las cuales acuden ante la Corte Interamericana de Derechos Humanos en pro de la reparación de sus perjuicios. En este trabajo se efectúa la revisión de un grupo de sentencias proferidas por la Corte Interamericana de Derechos Humanos, con el ánimo de analizar los elementos que configuran la responsabilidad internacional, acorde con el marco normativo previsto en el Sistema Interamericano de Derechos Humanos. Las disímiles posiciones adoptadas por la Corte Interamericana de Derechos Humanos al momento de atribuir el hecho internacionalmente ilícito al Estado colombiano, aun cuando tales hechos provienen de las actuaciones de los particulares -grupos de autodefensa-, se convierten en uno de los principales aspectos de estudio en este escrito.
\end{abstract}

\section{Palabras clave}

Deber de reparar, configuración de la responsabilidad, obligación internacional incumplida y hecho internacionalmente ilícito.

\begin{abstract}
The constant violation of human rights caused by the internal armed conflict in the Colombian State has generated a series of complaints from victims, who come before the Court of Human Rights towards the repair of damages. This paper makes a review of a group of decisions handed down by the Court of Human Rights, with the aim of analyzing the elements that make up the international responsibility, in accordance with the regulatory framework under the Inter-American Human Rights System. The disparate positions taken by the Inter-American Court at the time of the internationally wrongful act attributable to the Colombian State, even if such facts from the actions of individuals, groups of self-, become one of the main aspects of study in this paper.
\end{abstract}

\section{Key Words}

Duty to repair, configuration of responsibility, international obligation breached and the internationally wrongful act. 



\section{LA RESPONSABILIDAD INTERNACIONAL DEL ESTADO COLOMBIANO EN LA JURISPRUDENCIA DE LA CORTE INTERAMERICANA DE DERECHOS HUMANOS*}

Óscar Mauricio Reina García

\section{LA ESPECIAL SITUACIÓN DE LOS DERECHOS HUMANOS EN EL ESTADO COLOMBIANO}

El conflicto armado colombiano cumple casi 60 años, durante este tiempo ha sufrido unas variaciones inverosímiles, que lo han agudizado aún más. Lo que empezara con el surgimiento de grupos subversivos inconformes con las políticas públicas, se transformó en la existencia de otros grupos denominados paramilitares, que ante la ineficacia de las políticas militares estatales han tratado por sus propios medios de erradicar a aquéllos.

Esa lucha por el dominio territorial, económico y político de algunas regiones del país ha dado lugar a los más cruentos enfrentamientos entre los grupos armados ilegales y las fuerzas militares del Estado. Esta situación, ha ocasionado que la población civil padezca las más grandes barbaries y vejámenes en contra

* El texto aquí presentado analiza los elementos que configuran la responsabilidad internacional, acorde con el marco normativo previsto en el Sistema Interamericano de Derechos Humanos, a partir de la revisión de sentencias proferidas por la Corte Interamericana de Derechos Humanos, en desarrollo del trabajo de Investigación del Máster en Derecho Público (cursado por el autor), Universidad Carlos III de Madrid, España. 
de su dignidad humana. La mayoría de casos por demás sorprendentes, hacen de la situación la oportunidad adecuada para que se desconozcan los tratados sobre derechos humanos de los cuales el Estado colombiano es parte.

El presente trabajo se dirige a hacer un análisis de la responsabilidad internacional del Estado de conformidad con el marco jurídico del Sistema Interamericano de Derechos Humanos, para cumplir este cometido se realizará un examen de los casos que han sido resueltos por la Corte Interamericana de Derechos Humanos -en adelante la Corte o el Tribunal- en contra del Estado colombiano ${ }^{1}$.

El desarrollo de la investigación se efectuará en tres acápites, el primero de ellos dedicado a establecer las normas que fijan los deberes y obligaciones a los Estados en el Sistema Interamericano, en forma concreta la Convención Americana de Derechos Humanos y la Convención Americana para la Prevención y Sanción de la Tortura. En el segundo de los acápites se comentará el marco histórico del conflicto armado colombiano, así como también se relatará en una forma general los hechos que dieron lugar a los casos resueltos por la Corte, y que permiten entender la gravedad de las vulneraciones a los derechos humanos. En este punto se distinguirá entre las actuaciones que han sido materializadas por terceros o particulares y las que han sido desarrolladas por los funcionarios del Estado.

Finalmente, en el tercer acápite, que a su vez se subdivide en dos epígrafes, se examinará en el primero la configuración de la responsabilidad internacional, para lo cual se observarán las obligaciones internacionales que se han dejado de cumplir por parte del Estado y la atribución del hecho internacionalmente ilícito. En el segundo epígrafe se analizará el contenido de la responsabilidad, es decir, las medidas de reparación que han sido adoptadas por la Corte como forma de compensación del daño, las cuales quizás en el ámbito de los perjuicios materiales no sean innovadores, pero tratándose de los perjuicios inmateriales vienen a ser variadas y especiales de acuerdo con las circunstancias del caso.

1 Los casos son los siguientes: 1) Caso Caballero Delgado y Santa vs. Colombia, sentencia de 8 de Diciembre de 1995; 2) Caso las Palmeras vs. Colombia, sentencia de 6 de diciembre de 2001; 3) Caso 19 Comerciantes vs. Colombia, sentencia de 5 de julio de 2004; 4) Caso Gutiérrez Soler vs. Colombia, sentencia de 12 de septiembre de 2005; 5) Caso de la Masacre de Mapiripán vs. Colombia, sentencia de 15 de septiembre de 2005; 6) Caso de la Masacre de Pueblo Bello vs. Colombia, sentencia de 31 de enero de 2006; 7) Caso de la Masacre de Ituango vs. Colombia, sentencia de 1 de julio de 2006; 8) Caso de la Masacre de la Rochela vs. Colombia, sentencia de 11 de mayo de 2007; 9) Caso Escué Zapata vs. Colombia, sentencia de 4 de julio de 2007; 10) Caso Valle Jaramillo y otros vs. Colombia, sentencia de 27 de noviembre de 2008. 


\section{LA NORMATIVA DEL SISTEMA INTERAMERICANO}

El Estado colombiano adoptó la Convención Americana de Derechos Humanos -en adelante CADH- a través de la ley 16 de 1972, y a su vez, adoptó la Convención Americana para Prevenir y Sancionar la Tortura por medio de la ley 409 de $1997^{2}$. Son estas dos normas las que establecen las obligaciones que debe cumplir Colombia en el Sistema Interamericano, y conforman el marco jurídico de la responsabilidad internacional que es valorado por la Corte a la hora de declarar la existencia de responsabilidad y de imponer las sanciones correspondientes, en aquéllos casos en los que se alegue la vulneración de derechos por parte del Estado.

En este mismo sentido debe tenerse en cuenta las normas relativas al trámite de los procesos ante la Corte, tales como el Estatuto y el Reglamento del Tribunal y el Estatuto y Reglamento de la Comisión Interamericana de Derechos Humanos.

\section{CONTEXTO FÁCTICO E HISTÓRICO}

En las sentencias que se analizan, se puede distinguir dos grupos, el primero compuesto por seis de ellas ${ }^{3}$, que mantienen una identidad en cuanto a que la violación de los derechos humanos corre por cuenta de los particulares ${ }^{4}$, el segundo conformado por cuatro providencias que gozan, a su vez, de similitud, debido a que la conculcación de los derechos es efectuada por funcionarios del Estado ${ }^{5}$. No obstante lo anterior, en todos los fallos se encuentra un aspecto común, que corresponde a la violencia generada en el conflicto armado interno colombiano, por tal motivo se efectuará unas breves precisiones sobre el origen del mencionado conflicto, antes de especificar los hechos en cada grupo de sentencias.

El Estado colombiano a principios de los años 60 empezó a sortear una situación de inseguridad, ocasionada por el surgimiento de los grupos guerrilleros o subversivos, tales como las Fuerzas Armadas Revolucionarias de Colombia Ejército

2 La CADH fue suscrita en la conferencia especializada sobre derechos humanos que se llevó a cabo en San José (Costa Rica) del 7 al 22 de noviembre de 1969. Sobre los instrumentos del sistema interamericano puede consultarse "Los Derechos Humanos en Costa Rica". Ministerio de Relaciones Exteriores y Culto, 1999. Así mismo la página Web de la Corte Interamericana de Derechos Humanos "http://www.corteidh.or.cr".

3 Casos Masacre de la Rochela, 19 Comerciantes, Masacre de Pueblo Bello, Masacre de Mapiripán, Masacre de Ituango, Valle Jaramillo y otros.

4 Debe observarse que hasta este momento no se ha efectuado el análisis de la atribución del hecho internacionalmente ilícito, por tal motivo no se menciona al Estado.

5 Casos Las Palmeras, Caballero Delgado, Escué Zapata y Gutiérrez Soler. 
del Pueblo -FARC EP-, Ejército de Liberación Nacional -ELN- y el Ejército Popular de Liberación -EPL-. Con el ánimo de combatir tales grupos, el Estado hizo uso de los estados de excepción y de las facultades previstas en la legislación de excepción ${ }^{6}$.

Dentro de las medidas legislativas que se tomaron por el Estado se encuentra el decreto ley 3398 de 24 de diciembre de 1965, norma a la cual se le daría una vigencia permanente mediante la ley 48 de 1968. Esta normativa permitía que el Estado combatiera a los guerrilleros con la ayuda de los particulares, para lograr este objetivo se le permitió a éstos el porte de armas de uso privativo de las fuerzas militares, con lo cual surgen los grupos de seguridad privada o de autodefensa.

Inicialmente, es decir, durante las décadas de los 60 y 70, los grupos de autodefensa funcionaron tal y como había sido previsto por la normativa estatal; sin embargo, a mediados de los 80 se convirtieron en tropas dedicadas al tráfico de drogas, al cobro de impuestos y al ejercicio de la justicia por su propia mano, a través de sicarios que efectuaban ejecuciones extrajudiciales, principalmente contra todas aquellas personas que fueran considerados como auxiliadores de las guerrillas ${ }^{7}$.

Una vez que el gobierno colombiano verifica que las organizaciones de seguridad privada se convirtieron en otro foco de violencia, expide el decreto $\mathrm{N}^{\mathrm{o}} 0815$ de 1988 mediante el cual suspende el parágrafo $3^{\circ}$ del artículo 33 del decreto 3398 de 1965, que autorizaba el porte armas de uso privativo de las fuerzas militares a los particulares. Así mismo, a través del decreto 0180 de 27 de enero de 1988 tipificó como conducta penal la conformación de grupos de seguridad privada, con el fin de detener el auge de los mismos, y contener la fuerte situación de violencia y terrorismo que azotaba al país.

A pesar de los esfuerzos gubernamentales, los grupos de autodefensa que posteriormente se denominaron paramilitares o autodefensas unidas de Colombia

$6 \quad$ La Corte Interamericana en el caso Zambrano Vélez y otros vs. Ecuador estudia el tema referente a los estados de excepción y desarrolla una definición de dicho concepto "el estado de excepción es un mecanismo jurídico de los Estados, que se caracteriza por su naturaleza extraordinaria, que encuentra su justificación en la existencia de una situación excepcional de crisis o de emergencia que afecta a la población en la totalidad ó en una porción del territorio del país, y que constituye una amenaza a la vida organizada de la sociedad, motivo por el cual se faculta al poder ejecutivo para que profiera una legislación especial, que puede llegar a limitar o restringir los derechos y libertades constitucionales y legales de la persona, pero con el único fin de restaurar y preservar el estado de derecho y el sistema de democracia representativa", Corte Interamericana, Caso Zambrano Vélez y otros vs Ecuador sentencia de 4 de julio de 2007, párr. 13.

7 Las guerrillas colombianas financiaban su actividad insurgente mediante el cobro de impuestos a los latifundistas, luego con el surgimiento de los grupos de autodefensa, fueron éstos quienes empezaron a cobrar tales impuestos, bajo el pretexto de proteger las tierras y bienes, del actuar de los grupos subversivos. 
-AUC-, continuaron con sus actividades delincuenciales, ocuparon grandes porciones del territorio colombiano, y con una estructura militar similar a la de los grupos subversivos. Por esta razón a finales de la década de los noventa el Estado intentó adoptar medidas tendientes a la desmovilización y desarme de estos grupos en busca de la paz y la convivencia, lo cual sólo se alcanzó hasta el año 2005 con la expedición de la Ley 975 de 2005 -Ley de Justicia y Paz, que sirvió de soporte jurídico para la negociación, entrega, desarme y judicialización de los grupos de autodefensa.

Dicho esto, se procede a precisar los hechos de cada uno de los grupos de sentencias bajo estudio.

\section{La conducta de los particulares}

En estos casos la vulneración de los derechos humanos era efectuada por los paramilitares, los cuales se trasladaban en grupos de 20 o más hombres fuertemente armados hasta determinadas poblaciones y tomaban el control de las mismas durante uno o varios días 8 , a pesar que generalmente en dichas comunidades existía una fuerte presencia de las fuerzas militares del Estado, y que para llegar a ellas se debía pasar varios controles militares. De forma inexplicable durante el término en el cual se efectuaron las incursiones por parte de los grupos armados ilegales, las fuerzas militares no actuaron o no ejercieron su función de control en los retenes ${ }^{9}$.

Una vez tomado el control de la población o municipio los paramilitares procedían a intimidar a sus habitantes, aseguraban las oficinas de comunicaciones, impedían la circulación de las personas, y se dirigían a los lugares de residencia para sacar a la fuerza a sus moradores, los privaban de la libertad de acuerdo con los listados de personas que supuestamente eran considerados como auxiliadores de la guerrilla.

Estas personas que eran detenidas en forma arbitraria, eran interrogadas por sus supuestos vínculos con la guerrilla, eran golpeadas, torturadas y asesinadas. Las

8 En el caso de la masacre de Mapiripán la toma de la población duró 5 días desde el 15 de julio de 1997 al 20 del mismo mes y año. Corte Interamericana, Caso de la Masacre de Mapiripán, Párr. 96.40. En el caso de la masacre de Ituango la incursión paramilitar se extendió entre los días 22 de octubre y 12 de noviembre de 1997. Corte Interamericana, Caso de la Masacre de Ituango, Párr 125.57. En el caso de la Masacre de Pueblo Bello la toma de la población duró del 13 al 14 de enero de 1990. Corte Interamericana, Caso de la Masacre de Pueblo Bello, Párr. 95.30.

9 Así sucedió por ejemplo en el caso de la masacre de Pueblo Bello que a pesar de encontrarse esta zona dentro de una región declarada Jefatura Militar, los grupos paramilitares pudieron evadir el control militar. Corte Interamericana, Caso de la Masacre de Pueblo Bello, Párr. 95.63. En el caso de Mapiripán los grupos paramilitares -aproximadamente 120 hombres- llegaron por vía aérea, evadieron los controles aeroportuarios, fueron trasladados en camiones del ejército colombiano y evadieron a su vez los retenes militares o puestos de control. Corte Interamericana, Caso de la Masacre de Mapiripán, Párr. 96.32. 
evidencias y escena del crimen eran destruidas, los cadáveres arrojados a los ríos ${ }^{10}$ o sepultados en fosas comunes ${ }^{11}$. En algunos casos los grupos de autodefensa se apropiaban de los bienes de los pobladores, en el ataque a la localidad de Ituango los paramilitares tomaron entre 800 y 1200 cabezas de ganado caballar, mular y vacuno, además obligaron a las personas a que transportaran dichos bienes ${ }^{12}$.

A su vez, los grupos ilegales amenazaban a los familiares de las víctimas con quitarles la vida si no emigraban de sus municipios, por esta razón las personas abandonaban sus bienes, pues temían por su integridad, incluso en el caso de la masacre Ituango los paramilitares incineraron algunas viviendas ${ }^{13}$.

Finalmente, resulta importante exceptuar de los anteriores hechos el caso Valle Jaramillo y otros, el cual si bien guarda relación por tratarse de la vulneración de los derechos humanos por parte de particulares, no mantiene iguales características, toda vez que refiere a la privación de la libertad y posterior asesinato del defensor de derechos humanos Jesús María Valle Jaramillo por parte de grupos paramilitares, debido a que la víctima denunció la complicidad existente entre las fuerzas militares y los grupos de autodefensa en el mencionado caso de la masacre de Ituango ${ }^{14}$.

10 En el caso de la Masacre de Mapiripan la Corte Interamericana señaló que "Los paramilitares permanecieron en Mapiripán desde el 15 hasta el 20 de julio de 1997, lapso durante el cual impidieron la libre circulación a los habitantes de dicho municipio, y torturaron, desmembraron, desvisceraron y degollaron aproximadamente a 49 personas y arrojaron sus restos al río Guaviare. Además, una vez concluida la operación, las AUC destruyeron gran parte de la evidencia física, con el fin de obstruir la recolección de la prueba. Corte Interamericana, caso de la Masacre de Mapiripan, Párr. 96.39. En este mismo sentido en el caso de los 19 Comerciantes la Corte Interamericana expresó que "El 6 de octubre de 1987 en la noche o el 7 de octubre de 1987 miembros del referido grupo "paramilitar" que operaba en el Municipio de Puerto Boyacá dieron muerte a los 17 comerciantes, descuartizaron sus cuerpos y los lanzaron a las aguas del caño "El Ermitaño", afluente del río Magdalena, frente al sitio "Palo de Mango". Corte Interamericana, caso de la masacre de los 19 comerciantes, Párr. 85.f).

11 En el caso la Masacre de Pueblo Bello la Corte Interamericana señaló que "Posteriormente, los paramilitares trasladaron los cadáveres a las fincas "Las Tangas". Cerca de 22 cadáveres fueron transportados hacia otra playa del Río Sinú en la misma finca "Las Tangas", donde habrían sido enterrados". Corte Interamericana caso de la Masacre de Pueblo Bello, Párr. 95.41.

12 Corte Interamericana, caso de la Masacre de Ituango, PÁRR 125.85. Así mismo en el caso de los 19 comerciantes la Corte Interamericana expresó que "La mercancía de los comerciantes fue puesta a la venta en almacenes propiedad de dirigentes del referido grupo "paramilitar", los cuales se encontraban ubicados en Puerto Boyacá. Además, una parte de esta mercancía fue repartida entre los integrantes de dicho grupo y otra parte fue entregada como "regalos" a campesinos de la región”. Corte Interamericana, caso de los 19 comerciantes, Párr. 85.i.

13 Corte Interamericana, caso de la Masacre de Ituango, Párr. 125.79.

14 Corte Interamericana, caso Valle Jaramillo y otros, Párr. 2. 


\section{La conducta de los funcionarios del Estado}

Como ya se había anunciado, algunos de los hechos que fueron juzgados por la Corte en estos pronunciamientos, corresponden a vulneraciones de los derechos humanos por parte de los funcionarios del Estado. En estos casos las fuerzas militares irrumpían en las residencias de las personas ${ }^{15}$, las sacaban de allí, las detenían en forma arbitraria e ilícita. Durante la privación de la libertad las personas eran interrogadas por sus supuestas relaciones con los grupos subversivos, eran golpeadas, maltratadas físicamente y posteriormente ejecutadas en forma extrajudicial ${ }^{16}$.

En algunos casos la fuerza pública intentaba modificar la escena del crimen vestían a las víctimas con uniformes militares para hacerlos pasar como combatientes de los grupos subversivos ${ }^{17}$, en otros desaparecían sus restos mortales ${ }^{18}$.

Se exceptúa de este grupo de sentencias, el caso Gutiérrez Soler, el cual si bien el desconocimiento de las garantías fundamentales corrió por cuenta de la Policía Nacional, la violación a los derechos se produjo por la supuesta participación de la víctima en la comisión de un delito de extorsión, por lo cual fue golpeado, torturado y constreñido a confesar el mencionado delito ${ }^{19}$.

15 Corte Interamericana en el relato de los hechos en el caso Escué Zapata, aseveró "En el desarrollo de la operación los militares se dirigieron a la residencia del señor Germán Escué Zapata y sus familiares, ingresaron a la vivienda, registraron la misma, y mientras le preguntaban dónde estaban las armas y lo calificaban de guerrillero, lo golpearon. Germán Escué se encontraba con el torso desnudo, descalzo y en pantaloneta, cuando fue detenido y llevado por los militares hacia las montañas”. Corte Interamericana, caso Escué Zapata, Párr. 36 y 37.

16 Sobre los hechos en el caso Escué Zapata la Corte Interamericana, señaló "Después de haber caminado por un tiempo aproximado de veinte minutos, el Cabo Camacho Riaño se retrasó unos metros junto con Germán Escué Zapata, a quien golpeó en el estómago con la culata del fusil que portaba, haciendo que se doblegara. El señor Escué Zapata suplicó al Cabo Camacho Riaño que no lo matara, pero el Cabo retrocedió y le disparó varias veces causándole la muerte. Momentos después, su cadáver fue encontrado por sus familiares en el camino que de Vitoyó conduce a Loma Redonda". Corte Interamericana, Caso Escué Zapata, Párr. 38. Así también la Corte Interamericana al efectuar un relato de los hechos del caso de las palmeras manifestó "Las fuerzas del Ejército abrieron fuego desde un helicóptero e hirieron al niño Enio Quinayas Molina, en ese entonces de seis años, quien se dirigía a la escuela. La Policía detuvo en la escuela y en sus alrededores al maestro Cuarán Muchavisoy, a los trabajadores Cerón Gómez y Pantoja, a los hermanos Wilian Hamilton y Edebraes Cerón y a otra persona no identificada que podría ser Moisés Ojeda o Hernán Lizcano Jacanamejoy. La Policía Nacional ejecutó extrajudicialmente por lo menos a seis de estas personas." Corte Interamericana, caso Las Palmeras, Párr. 2. En este mismo sentido Corte Interamericana, caso Caballero Delgado, Párr. 53.b.

17 Corte Interamericana, caso de la Masacre de las Palmeras, Párr. 2.

18 Corte Interamericana, caso Caballero Delgado, Párr. 53. b.

19 Corte Interamericana, caso Gutiérrez Soler, Párr. 48.1 a 48.5. 


\section{El acceso a la justicia}

Un aspecto que es relevante en los casos tramitados ante el Tribunal contra el Estado colombiano, es el relacionado con el desconocimiento del derecho al acceso a la justicia. Esta garantía les permite a las personas que consideren vulnerados sus derechos que acudan ante las instancias judiciales con el ánimo de obtener el amparo de las mismas. En la mayoría de casos que se examinan en este trabajo, los familiares de las víctimas y el propio Estado intentaron a través de las instituciones judiciales que se diera inicio a las investigaciones penales -jurisdicción ordinaria y jurisdicción penal militar-, disciplinarias y contencioso administrativa.

Sin embargo, tales procedimientos se caracterizaron por ser prolongados en el tiempo ${ }^{20}$, por las amenazas a las personas e instituciones encargadas de las investigaciones $^{21}$, por las pocas sanciones y condenas que se imponían a los responsables ${ }^{22}$ y por la ausencia de responsabilidad en lo concerniente a la investigación de las conductas de los militares implicados ${ }^{23}$. La gravedad del desconocimiento del derecho al acceso a la justicia, en forma específica las garantías judiciales ${ }^{24}$, ocasionó

20 Véase al respecto de la Corte Interamericana los casos: la Masacre de las Palmeras, en el cual los procesos judiciales han durado más de 10 años, Párr. 58 y 64. Masacre de la Rochela, en el cual los procesos judiciales se han extendido durante 17 años, Párr. 143.

21 Consúltese al respecto, Corte Interamericana, Masacre de la Rochela, Párr. 165.

22 Consúltese al respecto, Corte Interamericana, los casos de: La masacre de Pueblo Bello, PÁRR 129. Valle Jaramillo, PÁRR 165, y Masacre de Ituango Párr. 324.

23 Consúltese al respecto, Corte Interamericana, los casos de: los 19 comerciantes, Párr. 165, 166. La Masacre de Mapiripán, Párr. 202. Masacre de la Rochela, Párr. 199, y Escué Zapata, Párr. 104. En la obra de Acosta Alvarado se encuentra una referencia a los aspectos que comprende o que se entienden incorporados al derecho al acceso a la Justicia “- El derecho a ser oído siempre que esté en cuestión la determinación, afección o garantía de un derecho, de cualquier tipo. Por lo tanto, el derecho a contar con los mecanismos judiciales (formales o informales) idóneos y suficientes para tal efecto. - El derecho a contar con las herramientas eficaces para la solución de las controversias y la sanción de los delitos. - El derecho a un recurso efectivo para la protección de los derechos humanos. - El derecho a un tribunal independiente e imparcial. - El derecho a contar con todas las posibilidades de preparar una defensa en igualdad de condiciones. El derecho a obtener una solución en un plazo razonable. - El derecho a una respuesta acorde con el ordenamiento jurídico, así como el derecho a que se cumpla lo previsto en ella." ACOSTA ALVARADO, P.A. y Otros. "El derecho de acceso a la justicia como norma de ius cogens según la jurisprudencia interamericana", en la obra colectiva Apuntes sobre el Sistema Interamericano, Temas de Derecho Público, Bogotá, Universidad Externado de Colombia, 2009, pp. 20 y 21.

24 En el trabajo de Acosta Alvarado se efectúa un análisis interesante del reconocimiento del carácter de norma de ius cogens por parte de la Corte Interamericana de Derechos Humanos a algunos aspectos del derecho de acceso a la justicia, y de las consecuencias que ello conlleva. Cfr. ACOSTA ALVARADO, P.A. y Otros. Op. cit. pp. 11 a 46. Sobre el derecho de acceso a la Justicia puede consultarse el artículo de Lozano, en el cual se realiza un estudio integral sobre los aspectos que evidencian la aplicación efectiva del derecho que se comenta en el Sistema Interamericano. Así mismo en este trabajo se reflexiona sobre los aspectos que le impiden a las personas el acceso al Sistema. Cfr. LOZANO, V.A. "Igualdad en el acceso al sistema interamericano de protección de los derechos humanos". En la obra colectiva Apuntes sobre el Sistema Interamericano, Temas de Derecho Público, Bogotá, Universidad Externado de Colombia, 2009, pp. 135 a 151. 
que la Corte efectuara un pronunciamiento especial al momento de atribuir el hecho internacionalmente ilícito al Estado, como se observará en el epígrafe 1.2 de este trabajo $^{25}$.

\section{CONTENIDO DE LAS SENTENCIAS}

\section{Epígrafe 1. Configuración de la responsabilidad}

\subsection{Obligación internacional incumplida}

La Corte en el análisis de los casos objeto de este trabajo de investigación, consideró que de conformidad con la obligación general prevista en el art. 1.1., de la $\mathrm{CADH}$ la cual dispone:

"Artículo 1. Obligación de Respetar los Derechos. 1. Los Estados Partes en esta Convención se comprometen a respetar los derechos y libertades reconocidos en ella y a garantizar su libre y pleno ejercicio a toda persona que esté sujeta a su jurisdicción, sin discriminación alguna por motivos de raza, color, sexo, idioma, religión, opiniones políticas o de cualquier otra índole, origen nacional o social, posición económica, nacimiento o cualquier otra condición social”.

El Estado colombiano dejó de cumplir las obligaciones o deberes de protección frente a los siguientes derechos:
a) $\mathrm{La} \operatorname{vida}^{26}$, b)
b) La integridad personal ${ }^{27}$,
c) Libertad personal ${ }^{28}$, d)
d) Garantías

25 Por este motivo se justifica la inclusión de un acápite referente al derecho al acceso a la justicia en el punto 3 de este trabajo correspondiente al contexto fáctico e histórico, a pesar que no guarden una estrecha relación conceptual.

26 CADH Art. 4.1. "1. Toda persona tiene derecho a que se respete su vida. Este derecho estará protegido por la ley y, en general, a partir del momento de la concepción. Nadie puede ser privado de la vida arbitrariamente."

27 CADH Art. 5.1. "1. Toda persona tiene derecho a que se respete su integridad física, psíquica y moral."

28 CADH, Art. 7 "1. Toda persona tiene derecho a la libertad y a la seguridad personal. 2. Nadie puede ser privado de su libertad física, salvo por las causas y en las condiciones fijadas de antemano por las Constituciones Políticas de los Estados Partes o por las leyes dictadas conforme a ellas. 3. Nadie puede ser sometido a detención o encarcelamiento arbitrarios. 4. Toda persona detenida o retenida debe ser informada de las razones de su detención y notificada, sin demora, del cargo o cargos formulados contra ella. 5. Toda persona detenida o retenida debe ser llevada, sin demora, ante un juez u otro funcionario autorizado por la ley para ejercer funciones judiciales y tendrá derecho a ser juzgada dentro de un plazo razonable o a ser puesta en libertad, sin perjuicio de que continúe el proceso. Su libertad podrá estar condicionada a garantías que aseguren su comparecencia en el juicio." 
Judiciales $^{29}$, e) derechos del niño $0^{30}$, f) Circulación y residencia ${ }^{31}$, g) $\operatorname{Propiedad~}^{32}$, h) Prohibición de trabajo forzoso ${ }^{33} y$, i) Prohibición de la tortura ${ }^{34}$.

\subsection{Atribución del hecho internacionalmente ilícito}

El Tribunal utiliza como primer argumento para la atribución del comportamiento al Estado, el carácter coercitivo de la CADH como marco de la responsabilidad internacional en el sistema interamericano ${ }^{35}$. El argumento anterior es complementado con el estudio de los artículos 1.1. y 2 del la CADH, los cuales radican en el Estado el deber de garantizar y velar por el cumplimiento de los derechos fundamentales reconocidos en ese instrumento internacional, constituyéndose dichas normas en el fundamento para el establecimiento de responsabilidad internacional a un Estado por la violación de la Convención ${ }^{36}$. Contrario sensu el incumplimiento de las

29 CADH, Art. 8 "1. Toda persona tiene derecho a ser oída, con las debidas garantías y dentro de un plazo razonable, por un juez o tribunal competente, independiente e imparcial, establecido con anterioridad por la ley, en la sustanciación de cualquier acusación penal formulada contra ella, o para la determinación de sus derechos y obligaciones de orden civil, laboral, fiscal o de cualquier otro carácter." Y art. 25 "1. Toda persona tiene derecho a un recurso sencillo y rápido o a cualquier otro recurso efectivo ante los jueces o tribunales competentes, que la ampare contra actos que violen sus derechos fundamentales reconocidos por la Constitución, la ley o la presente Convención, aún cuando tal violación sea cometida por personas que actúen en ejercicio de sus funciones oficiales."

$30 \mathrm{CADH}$, Art. 19 "Todo niño tiene derecho a las medidas de protección que su condición de menor requieren por parte de su familia, de la sociedad y del Estado."

$31 \mathrm{CADH}$, art. 22 "1. Toda persona que se halle legalmente en el territorio de un Estado tiene derecho a circular por el mismo y, a residir en él con sujeción a las disposiciones legales."

$32 \mathrm{CADH}$, art. 21 "Toda persona tiene derecho al uso y goce de sus bienes. La ley puede subordinar tal uso y goce al interés social. 2. Ninguna persona puede ser privada de sus bienes, excepto mediante el pago de indemnización justa, por razones de utilidad pública o de interés social y en los casos y según las formas establecidas por la ley.”

$33 \mathrm{CADH}$, art. 6 "1. Nadie puede ser sometido a esclavitud o servidumbre, y tanto éstas, como la trata de esclavos y la trata de mujeres están prohibidas en todas sus formas. 2. Nadie debe ser constreñido a ejecutar un trabajo forzoso u obligatorio. En los países donde ciertos delitos tengan señalada pena privativa de la libertad acompañada de trabajos forzosos, esta disposición no podrá ser interpretada en el sentido de que prohíbe el cumplimiento de dicha pena impuesta por juez o tribunal competente. El trabajo forzoso no debe afectar a la dignidad ni a la capacidad física e intelectual del recluido."

34 Convención Interamericana para prevenir y sancionar la tortura Art. $1^{\circ}$ "Los Estados partes se obligan a prevenir y a sancionar la tortura en los términos de la presente Convención.

35 Sobre el particular la Corte Interamericana ha expresado que: "La Convención Americana es un tratado multilateral mediante el cual los Estados Partes se obligan a garantizar y a hacer efectivos los derechos y libertades previstos en ella y a cumplir con las reparaciones que se dispongan. La Convención es la piedra fundamental del sistema de garantía de los derechos humanos en América" Corte Interamericana, caso las Palmeras, Párr.33. Sobre este aspecto véase al respecto la obra de, AGUIAR, A. Derechos humanos y responsabilidad Internacional del Estado.

36 Corte Interamericana, caso de la Masacre de Mapiripán, Párr. 107. 
obligaciones previstas en los artículos en comento dan lugar al surgimiento de la responsabilidad internacional.

Las mencionadas normas han sido interpretadas por la Corte de la siguiente forma,

“(...) el artículo 1.1 es fundamental para determinar si una violación de los derechos humanos reconocidos por la Convención puede ser atribuida a un Estado Parte. En efecto, dicho artículo pone a cargo de los Estados Partes los deberes fundamentales de respeto y garantía, de tal modo que todo menoscabo a los derechos humanos reconocidos en la Convención que pueda ser atribuido, según las reglas del Derecho internacional, a la acción u omisión de cualquier autoridad pública, constituye un hecho imputable al Estado que compromete su responsabilidad en los términos previstos por la misma Convención" ${ }^{37}$.

Ahora bien, el cumplimiento de las obligaciones previstas en los Arts. 1.1. y 2 de la $\mathrm{CADH}$, conlleva un comportamiento del Estado en dos sentidos ${ }^{38}$, el primero consistente en que no vulnere directamente los derechos y garantías reconocidos en la convención -acción-, y el segundo que el Estado no permita o tolere que otros personas desconozca tales garantías -omisión- ${ }^{39}$

El segundo argumento expuesto por la Corte se encuentra dirigido a atribuir los hechos internacionalmente ilícitos de los paramilitares al Estado colombiano ${ }^{40}$. Para llevar a cabo lo anterior la Corte parte del supuesto que fue el propio Estado quien promovió la creación de los grupos de autodefensa, bajo el amparo del decreto 3398

37 Corte Interamericana, caso de la Masacre de Mapiripán, Párr. 107. En este mismo sentido puede verse Corte Interamericana, caso de la Masacre de Pueblo Bello, Párr. 111.

38 La conducta reprochable al Estado puede haberse generado por acciones u omisiones, sobre este tema en particular puede consultarse, CRAWFORD, J. Los artículos de la Comisión de Derecho Internacional sobre la responsabilidad Internacional del Estado, P. 120, ediciones Dykinson, S.L., Madrid, 2004.

39 La Corte Interamericana, ha señalado sobre este tema "Es decir, el origen de la responsabilidad internacional del Estado se encuentra en "actos u omisiones de cualquier poder u órgano de éste, independientemente de su jerarquía, que violen la Convención Americana”, y se genera en forma inmediata el ilícito internacional atribuido al estado. Para establecer que se ha producido una violación de los derechos consagrados en la Convención no se requiere determinar, como ocurre en el derecho penal interno, la culpabilidad de sus autores o su intencionalidad, y tampoco es preciso identificar individualmente a los agentes a los cuales se atribuyen los hechos violatorios. Es suficiente la demostración de que ha habido apoyo o tolerancia del poder público en la infracción de los derechos reconocidos en la convención, u omisiones que hayan permitido la perpetración de esas violaciones.” Corte Interamericana, caso de la Masacre de Mapiripán, Párr. 110.

40 En los casos en que la vulneración de los derechos humanos fue ocasionado por los funcionarios del Estado, basta con el primer argumento para atribuir la responsabilidad internacional al mismo, por tal motivo no se profundizará sobre el particular. Véase, Corte Interamericana, caso Caballero Delgado, Párr. 54,55 y 56. Así mismo, Corte Interamericana, caso Escué Zapata, Párr. 11., y Corte Interamericana, caso Gutiérrez Soler, Párr. 52. 
de 1965, permitiéndole el porte de armas de uso privativo de las fuerzas militares ${ }^{41}$. Lo anterior a juicio del Tribunal se constituyó en la asignación de funciones militares a particulares ${ }^{42}$

Si bien la anterior posición de la Corte radica en forma directa la responsabilidad internacional por los hechos de los grupos de autodefensa en el Estado colombiano, dicho enfoque ha sido variado en los pronunciamientos recientes de esa Corporación, en los cuales ha considerado que el Estado propició la formación de los grupos paramilitares, y no pudo posteriormente controlar el auge de los mismos, por lo tanto, ha creado objetivamente una situación de riesgo ${ }^{43}$.

41 Puede consultarse al respecto los siguientes casos: Masacre de la Rochela, Párr. 101. Masacre de Ituango, Párr. 134. Valle Jaramillo y otros, Párr. 76.

42 La Corte Interamericana en caso de la Masacre de la Rochela, Párr. 102, se pronunció sobre este aspecto "La Corte observa que en el presente caso el Estado permitió la colaboración y participación de particulares en la realización de ciertas funciones (tales como patrullaje militar de zonas de orden público, utilizando armas de uso privativo de las fuerzas armadas o en desarrollo de actividades de inteligencia militar), que por lo general son de competencia exclusiva del Estado y donde éste adquiere una especial función de garante. En consecuencia, el Estado es directamente responsable, tanto por acción como por omisión, de todo lo que hagan estos particulares en ejercicio de dichas funciones, más aún si se tiene en cuenta que los particulares no están sometidos al escrutinio estricto que pesa sobre un funcionario público respecto al ejercicio de sus funciones. Fue de tal magnitud esta situación en la que particulares colaboraron en el desarrollo de dichas funciones, que cuando el Estado trató de adoptar las medidas para enfrentar el desborde en la actuación de los grupos paramilitares, estos mismos grupos, con el apoyo de agentes estatales, atentaron contra los funcionarios judiciales". Esta atribución de responsabilidad que fuera realizada por la Corte, se identifica con lo previsto en el artículo $5^{\circ}$ del proyecto de artículos sobre responsabilidad del Estado por hechos internacionalmente ilícitos: "Comportamiento de una persona o entidad que ejerce atribuciones del poder público", dicha norma prevé que se pueda atribuir al Estado conductas de particulares que ejercen funciones del poder público, autorizadas por el propio Estado, como sucede en el caso del Estado colombiano que permitió la entrega de armas de uso privativo de los fuerzas militares a los particulares, para que apoyaran la ofensiva contra los grupos subversivos.

43 Véase al respecto los casos: Masacre de Pueblo, Párr. 126. En la cual la Corte Interamericana expresó:" Sin embargo, esas medidas no se vieron traducidas en la desactivación concreta y efectiva del riesgo que el propio Estado había contribuido a crear. Con la interpretación que durante años se le dio al marco legal, el Estado propició la creación de grupos de autodefensas con fines específicos, pero éstos se desbordaron y empezaron a actuar al margen de la ley. De este modo, al haber propiciado la creación de estos grupos el Estado creó objetivamente una situación de riesgo para sus habitantes y no adoptó todas las medidas necesarias ni suficientes para evitar que éstos puedan seguir cometiendo hechos como los del presente caso. La declaratoria de ilegalidad de éstos debía traducirse en la adopción de medidas suficientes y efectivas para evitar las consecuencias del riesgo creado. Esta situación de riesgo, mientras subsista, acentúa los deberes especiales de prevención y protección a cargo del Estado en las zonas en que exista presencia de grupos de protección a cargo del Estado en las zonas en que exista presencia de grupos paramilitares, así como la obligación de investigar con toda diligencia actos u omisiones de agentes estatales y de particulares que atenten contra la población civil". En el mismo sentido pueden consultarse lo casos, Valle Jaramillo, PÁRR 80, y Masacre de Ituango, Párr. 130. 
Como consecuencia de la creación del riesgo ${ }^{44}$, el Estado debe adoptar unas medidas de protección especiales, que impida la vulneración de los derechos y garantías previstos en la $\mathrm{CADH}$, por parte de las autodefensas, de lo contrario esos hechos serán atribuidos al Estado, por la tolerancia y omisión frente a los mismos y en este orden de ideas sería llamado a responder internacionalmente ${ }^{45}$.

Es posible sintetizar lo expuesto en este epígrafe y señalar que para la Corte la atribución de la responsabilidad del Estado encuentra su fundamento en el carácter obligatorio de la CADH como norma especial del Sistema Interamericano, y en el deber de protección y garantía previsto en los artículos 1.1, y 2 de dicho instrumento, obligación que se encuentra cualificada o reviste un carácter específico en el caso colombiano debido a la situación de riesgo que ha sido propiciada por el propio Estado, por tal motivo el deber de protección y prevención ha de ser mayor, de lo contrario es posible atribuir al Estado la conducta de los particulares, por la vulneración de los derechos a la vida, la integridad personal, la libertad personal, los derechos del niño, circulación y residencia, propiedad, prohibición de trabajo forzoso y la prohibición de la tortura, de los habitantes de las regiones donde tales grupos ejercen influencia.

Por otra parte, es necesario que se observe que la Corte ha efectuado un análisis particular, en lo referente a la atribución de responsabilidad internacional al Estado por la vulneración del art. 8 y 25 de la CADH "Garantías Judiciales" a los familiares de las víctimas ${ }^{46}$. La responsabilidad se encuentra fundamentada por el Tribunal en la ausencia de recursos efectivos en el aparato jurisdiccional para

44 Sobre la teoría del riesgo, pero en materia de responsabilidad extracontractual del Estado puede consultarse la obra de, PÉLÁEZ GUTIÉRREZ, J.C. Reflexiones sobre los fundamentos de la jurisprudencia administrativa francesa y colombiana en materia de actos de terrorismo. P. 91. Instituto de Estudios Constitucionales Carlos Restrepo Piedrahita, Bogotá, 2000.

45 La Corte en el caso de la Masacre de Mapiripán, Párr. 111, tomó este criterio al considerar que, "Dicha responsabilidad internacional puede generarse también por actos de particulares en principio no atribuibles al Estado. Los Estados Partes en la Convención tienen obligaciones erga omnes de respetar las normas de protección y de asegurar la efectividad de los derechos allí consagrados en toda circunstancia y respecto de toda persona. Esas obligaciones del Estado proyectan sus efectos más allá de la relación entre sus agentes y las personas sometidas a su jurisdicción, pues se manifiestan también en la obligación positiva del Estado de adoptar las medidas necesarias para asegurar la efectiva protección de los derechos humanos en las relaciones inter-individuales. La atribución de responsabilidad al Estado de actos de particulares puede darse en casos en que el Estado incumple, por acción u omisión de sus agentes cuando se encuentren en posición de garantes, esas obligaciones erga omnes contenidas en los artículos 1.1 y 2 de la Convención."

46 Sobre el tema de las garantías judiciales en el sistema interamericano puede verse de la Corte Interamericana, las opiniones consultivas OC-8/87 de 30 de enero de 1987 y OC- 9/87 de 6 de Octubre de 1987. 
realizar las correspondientes reclamaciones ${ }^{47}$, toda vez que la duración de los mismos superaba el plazo razonable de acuerdo con los criterios que han sido fijados por esa corporación ${ }^{48}$, trámites que se extendían durante 10 o más años ${ }^{49}$.

Otro argumento que utiliza la Corte para determinar el incumplimiento del Estado frente al desconocimiento de las garantías judiciales, es la improcedencia del juzgamiento de la conducta de los militares implicados por la jurisdicción penal militar ${ }^{50}$, cuando tales comportamientos consisten en la violación de los derechos humanos ${ }^{51}$. Bajo las anteriores consideraciones, la Corte determinó que el conocimiento por parte de la Jurisdicción Penal Militar de las investigaciones

47 Sobre los mecanismos de protección de los derechos humanos puede consultarse, FIX ZAMUDIO, H. La protección procesal de los derechos humanos ante las jurisdicciones nacionales, Editorial Civitas, 1982.

48 En el caso las Palmeras la Corte Interamericana expresó "La Corte ha establecido el criterio de que un período de cinco años transcurrido desde el momento del auto de apertura del proceso rebasaba los límites de la razonabilidad". Sobre este aspecto la Corte Interamericana ha establecido que deben observarse 3 elementos para establecer si un plazo es razonable o no: 1. La complejidad del asunto, 2. la actividad procesal del interesado, y 3. la conducta de las autoridades judiciales. Corte Interamericana, Caso Valle Jaramillo, Párr. 155.

49 Véase al respecto de la Corte Interamericana los casos: la Masacre de las Palmeras, en el cual los procesos judiciales han durado más de 10 años, Párr. 58 y 64. Masacre de la Rochela, en el cual los procesos judiciales se han extendido durante 17 años, Párr. 143.

50 Sobre este tema la Corte Interamericana, en el caso las Palmeras, Párr. 51, señaló "Con respecto a la jurisdicción penal militar, la Corte ya ha establecido que en un Estado democrático de derecho dicha jurisdicción ha de tener un alcance restrictivo y excepcional y estar encaminada a la protección de intereses jurídicos especiales, vinculados con las funciones que la ley asigna a las fuerzas militares. Por ello, sólo se debe juzgar a militares por la comisión de delitos o faltas que por su propia naturaleza atenten contra bienes jurídicos propios del orden militar".

51 En el caso de los 19 comerciantes, Párr. 173. La Corte Interamericana expresó frente a este tema "En el presente caso el derecho a un debido proceso debe ser analizado de acuerdo al objeto y fin de la Convención Americana, cual es la eficaz protección de la persona humana, es decir, debe hacerse una interpretación pro persona. No hay lugar a dudas de que la participación que pudieran haber tenido los militares investigados al "conoc[er] de las actividades delictivas de grupos al margen de la Ley, [...] presta[ndoles] apoyo y cohonesta[ndo] los acontecimientos delictivos" (supra párr. 169) de la detención, la desaparición y la muerte de los 19 comerciantes, así como en la sustracción de sus vehículos y mercancías, no tiene una relación directa con un servicio o tarea militar. Esta Corte considera que la anterior atribución de competencia de la jurisdicción penal militar para conocer de los supuestos delitos perpetrados en perjuicio de los 19 comerciantes por miembros del Ejército, quienes ya estaban siendo investigados por la jurisdicción penal ordinaria, no respetó los parámetros de excepcionalidad y el carácter restrictivo que caracteriza a la jurisdicción castrense, ya que dicha jurisdicción no era competente para conocer de tales hechos, todo lo cual contravino el principio del juez natural que forma parte del derecho a un debido proceso y del derecho de acceso a la justicia, consagrados en los artículos 8.1 y 25 de la Convención Americana." 
correspondientes, desconocían los principios al juez natural, debido proceso y el derecho al acceso a la justicia ${ }^{52}$.

En este orden de ideas se puede concluir que la atribución de la responsabilidad del Estado colombiano por la vulneración de las garantías judiciales, fue fundamentada por la Corte en la ausencia de recursos efectivos debido al plazo irrazonable en el trámite de los mismos, y en el desconocimiento del principio del juez natural como consecuencia del juzgamiento por parte de la jurisdicción castrense, de las conductas de los militares que desconocieron los derechos humanos de la población.

\section{Epígrafe 2. Contenido de la responsabilidad}

En el Sistema Interamericano el marco de la reparación de los perjuicios, derivado de la declaración de la responsabilidad internacional del Estado, se encuentra en el art. 63.1 de la CADH que prevé,

"1. Cuando decida que hubo violación de un derecho o libertad protegidos en esta Convención, la Corte dispondrá que se garantice al lesionado en el goce de su derecho o libertad conculcados. Dispondrá asimismo, si ello fuera procedente, que se reparen las consecuencias de la medida o situación que ha configurado la vulneración de esos derechos y el pago de una justa indemnización a la parte lesionada".

El establecimiento de la norma en comento obedece a la existencia de un principio fundamental de derecho internacional, según el cual al producirse un hecho ilícito internacional que sea atribuible a un Estado, surge la responsabilidad internacional por el desconocimiento del contenido obligacional, debiendo dicho estado reparar y hacer cesar sus consecuencias, este es el llamado deber de reparar ${ }^{53}$.

La Corte define el resarcimiento de los perjuicios de la siguiente manera:

"Las reparaciones consisten en las medidas que tienden a hacer desaparecer los efectos de las violaciones cometidas. Su naturaleza y su monto dependen

52 Sobre este punto vale la pena traer a colación la sentencia C-358 de 1997 de la Corte Constitucional colombiana, que fue citada por la Corte Interamericana al momento de atribuir la responsabilidad al Estado, "para que un delito sea de competencia de la justicia penal militar [...] el hecho punible debe surgir como una extralimitación o un abuso de poder ocurrido en el marco de una actividad ligada directamente a una función propia del cuerpo armado. [...] Si desde el inicio el agente tiene propósitos criminales, y utiliza entonces su investidura para realizar el hecho punible, el caso corresponde a la justicia ordinaria, incluso en aquellos eventos en que pudiera existir una cierta relación abstracta entre los fines de la Fuerza Pública y el hecho punible del actor. [...] E 1 vínculo entre el hecho delictivo y la actividad relacionada con el servicio se rompe cuando el delito adquiere una gravedad inusitada, tal como ocurre con los llamados delitos de lesa humanidad. En estas circunstancias, el caso debe ser atribuido a la justicia ordinaria, dada la total contradicción entre el delito y los cometidos constitucionales de la Fuerza Pública”. Caso de los 19 comerciantes, Párr. 168.

53 Véase Corte Interamericana, Caso de la Masacre de Mapiripán, Párr. 243. 
del daño ocasionado en los planos material e inmaterial. Las reparaciones no pueden implicar ni enriquecimiento ni empobrecimiento para la víctima o sus sucesores" ${ }^{\prime 5}$.

No obstante que, tal resarcimiento se debe dirigir a la reparación in natura o restitutio in integrum, es decir, a tratar en lo posible de restablecer la situación anterior o inicial.

Ahora bien, en el evento que en el orden interno se hayan reparado los perjuicios, tales indemnizaciones son reconocidas por el Tribunal con un criterio de favorabilidad hacia el beneficiario, toda vez que si la reparación fijada por la justicia interna es menor que la fijada por la Corte, dicha indemnización debe ser complementada por el Estado, pero en el caso opuesto cuando la reparación establecida en el orden interno supera la determinada por el órgano jurisdiccional del Sistema Interamericano, no hay lugar a devoluciones por parte del beneficiario ${ }^{55}$.

A continuación se efectúa una clasificación y descripción de las medidas de reparación que han sido ordenadas por la Corte, en sus dos aspectos material e inmaterial, y que se enderezan a la reparación integral del daño por la vulneración de los derechos humanos.

\subsection{Daño Material}

El daño material en términos breves es aquel que supone un detrimento económico para la víctima, es reconocido por el Tribunal en sus dos expresiones, el daño emergente y la pérdida de ingresos o lucro cesante. Tales daños son valorados o medidos en la moneda estadounidense. ${ }^{56}$

Este tipo de daño material ha sido entendido como aquél

"el cual supone la pérdida o detrimento de los ingresos de las víctimas, los gastos efectuados con motivo de los hechos y las consecuencias de carácter pecuniario que tengan un nexo causal con los hechos del caso sub judice (...)"'57.

\subsubsection{Daño Emergente}

El daño emergente se configura "Hay daño emergente cuando un bien económico (dinero, cosas, servicios) salió o saldrá del patrimonio de la víctima..." ${ }^{58}$. En lo

\footnotetext{
54 Corte Interamericana, Caso de la Masacre de Mapiripán, Párr. 244.

55 Corte Interamericana, Caso de la Masacre de la Rochela, Párr. 250

56 Corte Interamericana, Caso de los 19 comerciantes, Párr. 243

57 Corte Interamericana, caso de los 19 comerciantes, Párr. 236

58 HENAO PÉREZ, J.C. "El Daño, análisis comparativo de la responsabilidad extracontractual del estado en derecho colombiano y francés", p. 197, ediciones Universidad Externado de Colombia, quinta reimpresión, Bogotá 2005
} 
referente a este daño el Tribunal ha enfocado sus pronunciamientos a destacar la importancia de los elementos probatorios, que permitan establecer el carácter cierto de los $\operatorname{mismos}^{59}$. Sin embargo en algunos pronunciamientos ante la ausencia de pruebas por las características especiales de los casos, ha procedido a fijar este rubro en equidad ${ }^{60}$.

\subsubsection{Pérdida de Ingresos}

En lo concerniente a este tipo de daños vale la pena destacar dos aspectos que son novedosos en los casos objeto de estudio, el primero de ellos es la presunción de ingresos cuando no existen los correspondientes materiales probatorios. Para calcular tales ingresos, la Corte toma como punto de partida el salario mínimo legal mensual vigente ${ }^{61}$.

El segundo, es el reconocimiento de pérdidas de los ingresos dejados de percibir por parte de los menores o niños fallecidos, a favor de sus familiares, aun cuando no existan pruebas del ejercicio de actividad laboral alguna ${ }^{62}$. De acuerdo con esto la Corte presume la existencia de una actividad laboral o comercial y sus ingresos en cabeza de los menores de edad y prolonga o extiende los efectos económicos de la actividad a futuro, con lo cual se configura el reconocimiento de un perjuicio no consolidado con base en una situación inexistente - actividad laboral- ${ }^{63}$.

La anterior posición es cuestionable debido a la falta de certeza del perjuicio, que se ocasiona en primer lugar por la inexistencia de la prueba del ejercicio de la actividad laboral o económica, y en segundo lugar, porque en caso que se presuma la actividad, no se cuenta con la seguridad de saber si los ingresos provenientes de la misma vayan a ser destinados a los gastos de la familia, aspecto que resulta importante al ubicarse en el contexto de las personas a las cuales se les va a estimar el perjuicio "niños", por cuanto que no podría considerarse que tengan cónyuge o hijos beneficiarios de tal indemnización.

59 Cfr. Corte Interamericana, Caso de la Masacre de Pueblo Bello, Párr. 247

60 Cfr. Corte Interamericana, Caso de la Masacre de Mapiripán, Párr. 267. Lo anterior, por que como consecuencia de las ejecuciones de las víctimas, los familiares debían desplazarse de sus viviendas hacia otros municipios por amenazas a su vida y establecer allí su residencia, por tal motivo no era posible que hubiesen recolectado las pruebas correspondientes.

61 Cfr. Caso de los 19 comerciantes, Párr. 240

62 Cfr. Corte Interamericana caso de la Masacre de Mapiripán Párr. 276

63 En la obra de Henao Pérez se estudia el carácter cierto del perjuicio en la responsabilidad extracontractual del Estado. HENAO PÉREZ, J.C. "El Daño, análisis comparativo de la responsabilidad extracontractual del estado en derecho colombiano y francés", p. 129 a 188, ediciones Universidad Externado de Colombia, quinta reimpresión, Bogotá 2005. 


\subsection{Daño Inmaterial}

El perjuicio inmaterial comprende

"el sufrimiento y las aflicciones causadas a las víctimas directas o a sus allegados, como el menoscabo de valores muy significativos para las personas, así como las alteraciones, de carácter no pecuniario, en las condiciones de existencia de las víctimas" ${ }^{\prime \prime}$,

tales padecimientos no son susceptibles de una valoración económica exacta, no obstante lo anterior con el ánimo de llevar a cabo la reparación integral, se efectúa la compensación de los mismos por dos vías, las cuales se precisan en los acápites siguientes ${ }^{65}$.

\subsubsection{Valorable en forma económica}

Esta clase de perjuicio, como su nombre lo indica corresponde al pago de una cantidad de dinero que es fijada en términos de equidad por el operador judicial. Sobre este punto vale la pena destacar la tesis en la cual se reconoce que el daño es más intenso y, por ende, la cuantía por concepto de estos perjuicios debe ser mayor o tiene un plus, cuando es un niño quien ha sido la víctima ${ }^{66}$.

\subsubsection{No valorable en forma económica}

Debido a su naturaleza no pecuniaria, este tipo de perjuicio se repara a través de la realización de actos u obras que tengan una gran incidencia pública y se persigue como finalidades la recuperación de la memoria de las víctimas, el reconocimiento de su dignidad, brindarles un consuelo a los deudos y que la situación no se vuelva a presentar, éstas medidas se han denominado como: Otras formas de reparación.

Estos medios de reparación no son taxativos y dependerán de las circunstancias de cada caso concreto, a continuación se señalan las que han sido impuestas al Estado colombiano de acuerdo con los casos que se estudian: a) obligación de investigar, juzgar y sancionar a las personas responsables de la vulneración de los derechos humanos ${ }^{67}$; b) obligación de proteger a los jueces, investigadores, testigos y familiares ${ }^{68}$; c) asistencia médica y psicológica para las víctimas y sus

64 Corte Interamericana, caso de la Masacre de Mapiripán Párr. 282.

65 Véase, Corte Interamericana caso de la Masacre de Ituango Párr. 383.

66 Corte Interamericana, caso de la Masacre de Ituango, Párr. 390. B.

67 Corte Interamericana, caso de la Masacre de la Rochela, Párr. 286, a. Sobre el deber de investigación vale la pena señalar que la Corte Interamericana ha creado el concepto de cosa juzgada fraudulenta, según el cual los fallos que se profieran en los juicios y que no han respetado el debido proceso de acuerdo a los estándares de la convención americana, tales decisiones no hacen tránsito a cosa juzgada y no pueden ser invocada por el estado como eximente de la obligación de investigar. Corte Interamericana, caso Gutiérrez Soler, Párr. 98. 
familiares $^{69} ;$ d) educación en derechos humanos a la fuerzas militares ${ }^{70} ;$ e) obligación de efectuar las búsquedas de los restos mortales de las víctimas ${ }^{71} ;$ f) construcción de un monumento en memoria de las víctimas ${ }^{72}$; g) acto público de reconocimiento de responsabilidad internacional por parte del Estado y de desagravio de los familiares de las víctimas ${ }^{73}$; h) identificar a las víctimas ${ }^{74}$; i) crear un mecanismo oficial de seguimiento del cumplimiento de las reparaciones ordenadas ${ }^{75}$; j) garantías de seguridad a las personas que desean retornar a sus municipios ${ }^{76}$; $\mathrm{k}$ ) publicación de la sentencia - acápite de hechos probados y puntos resolutivos- en el Diario Oficial y en un Diario de amplia circulación nacional ${ }^{77}$; 1) obligación de desarrollar una política de protección a los defensores de derechos humanos ${ }^{78} ; \mathrm{m}$ ) becas de estudio para los familiares de la víctima ${ }^{79} ; n$ ) creación de un fondo de desarrollo comunitario en memoria de la víctima ${ }^{80}$; ñ) implementación de los parámetros del manual para la investigación y documentación eficaces de la tortura y otros tratos o penas crueles, inhumanos o degradantes ("el Protocolo de Estambul") ${ }^{81}$; o) fortalecimiento de los controles en centros de detención ${ }^{82} ; \mathrm{y}$ ) desarrollo de un programa de vivienda ${ }^{83}$.

\subsection{Beneficiarios}

El Tribunal ha establecido un orden de distribución o preferencia para los beneficiarios o familiares de las víctimas fallecidas, quiénes son los llamados a recibir los daños materiales en lo referente a la pérdida de ingresos y el daño inmaterial valorable en forma económica. La forma de repartir es la siguiente,

“a) el cincuenta por ciento $(50 \%)$ de la indemnización se repartirá por partes iguales entre los hijos e hijas de las víctimas; b) el cincuenta por ciento (50\%) de la indemnización deberá ser entregado a quien fuera cónyuge, o compañera o compañero permanente de la víctima al momento de la muerte de ésta; c) en el caso de que la víctima no tuviere hijos o hijas, ni cónyuge o compañera o compañero permanente, el cincuenta por ciento $(50 \%)$ de la indemnización se entregará a sus padres y se dividirá entre ellos en partes iguales. Si uno de ellos

69 Corte Interamericana, caso de la Masacre de la Rochela, Párr. 298, c.

70 Corte Interamericana, caso de la Masacre de la Rochela, Párr. 303, d.

71 Corte Interamericana, caso de los 19 Comerciantes, Párr. 264, b.

72 Corte Interamericana, caso de los 19 Comerciantes, Párr. 272, c.

73 Corte Interamericana, caso de los 19 Comerciantes, Párr. 274, d.

74 Corte Interamericana, caso de la Masacre de Mapiripán, Párr. 304, a.

75 Corte Interamericana, caso de la Masacre de Mapiripán, Párr. 311, c.

76 Corte Interamericana, caso de la Masacre de Mapiripán, Párr. 313, e.

77 Corte Interamericana, caso de la Masacre de Mapiripán, Párr. 318, i.

78 Corte Interamericana, caso Valle Jaramillo, Párr. 227, d.

79 Corte Interamericana, caso Valle Jaramillo, Párr. 227, f.

80 Corte Interamericana, caso Escué Zapata, Párr. 168, b.

81 Corte Interamericana, caso Gutiérrez Soler, Párr. 109, e.

82 Corte Interamericana, caso Gutiérrez Soler, Párr. 111, f.

83 Corte Interamericana, caso de la Masacre de Ituango, Párr. 407, e. 
hubiere muerto, la parte que le corresponde acrecerá a la del otro. El restante cincuenta por ciento $(50 \%)$ se repartirá en partes iguales entre los hermanos de la víctima; y d) en el evento que no existieren familiares en alguna o algunas de las categorías definidas en los literales anteriores, lo que le hubiere correspondido a los familiares ubicados en esa o esas categorías, acrecerá proporcionalmente a la parte que les corresponda a las restantes" $" 44$.

Además de las personas enunciadas en el anterior orden, en los casos que se estudian se ha adoptado un criterio material, en el sentido de reconocer como beneficiarios a personas que si bien no tenían el grado de parentesco exigido en tal orden, gozaban de un trato o un vínculo estrecho con la víctima, tal y como se hizo en el caso de los 19 comerciantes en el cual se reconoció a un primo de la víctima como si fuese hermano porque que convivían en la misma casa ${ }^{85}$. Se ha reconocido también la posibilidad de compartir la indemnización cuando la víctima tenía al mismo tiempo cónyuge y compañera permanente, caso en el cual la correspondiente porción será repartida en partes iguales ${ }^{86}$.

\section{CONCLUSIONES}

La responsabilidad internacional de los Estados en el Sistema Interamericano de derechos humanos, se fundamenta en el marco jurídico definido por la Convención Americana de derechos Humanos, así como también en los principios generales del derecho internacional encargados de regular el tema.

El fundamento para atribuir el hecho internacionalmente ilícito a un Estado, se encuentra en los artículos 1.1. y 2 de la $\mathrm{CADH}$, toda vez que en estas disposiciones se consagra el deber de protección y cumplimiento del contenido obligacional previsto en el mencionado instrumento internacional.

La atribución de un hecho internacionalmente ilícito al Estado puede hacerse aún por las conductas desplegadas por terceros, si se demuestra que ha sido el propio Estado el que ha promovido o patrocinado la creación de esos grupos de particulares, con lo cual coloca en una situación de riesgo a sus habitantes, y si se acredita que a pesar de tales circunstancias anormales, el Estado no toma las medidas de protección especiales para salvaguardar los derechos y garantías fundamentales previstos en la $\mathrm{CADH}$.

Las vulneraciones a los derechos humanos conforme con los artículos 8 y 25 de la $\mathrm{CADH}$, obligan al Estado a ofrecer a las víctimas unas garantías judiciales que

84 Corte Interamericana, caso de la Masacre de la Rochela, Párr. 237.

85 Corte Interamericana, caso de la Masacre de la Rochela, Párr. 232. En este mismo sentido en el caso de la masacre de Mapiripán reconoció como hijo a un hijastro de la víctima, Corte Interamericana, Mapiripán, Párr. 259, a.

86 Corte Interamericana, Caso de la Masacre de Pueblo Bello, Párr. 240, a. 
se desarrollen en un plazo razonable, y sean respetuosas de los principios al juez natural, debido proceso y el derecho al acceso a la administración de justicia, con el ánimo de encontrar la verdad y proceder a una reparación integral.

La Jurisdicción Penal Militar no es competente para conocer de los delitos que configuren graves vulneraciones a los derechos humanos, en los cuales se vean implicados los miembros de las fuerzas militares.

Una vez se configure la responsabilidad internacional en cabeza del Estado, éste se encuentra en el deber de reparar integralmente el perjuicio que haya causado el hecho internacionalmente ilícito que se le atribuye, conforme a lo contemplado por el art. 63.1 de la CADH.

La reparación integral del perjuicio, comprende el reconocimiento del daño material en sus dos expresiones emergente y pérdida de ingresos, y el daño inmaterial, de igual forma en sus dos modalidades el valorable económicamente y el que no es posible estimar por esta vía.

La Corte Interamericana de Derechos Humanos ha establecido una variada forma de reparar los perjuicios inmateriales no susceptibles de valoración económica, de acuerdo con las circunstancias de cada caso, y con la finalidad primordial de dar a conocer al público el hecho internacionalmente ilícito cometido por el estado, rescatar la memoria de las víctimas y dar un consuelo a los familiares, de las mismas.

\section{REFERENCIAS}

Aguiar, A. (1997). Derechos humanos y responsabilidad Internacional del Estado.

Acosta Alvarado, P.A. y otros. (2009). El derecho de acceso a la justicia como norma de ius cogens según la jurisprudencia interamericana, en la obra colectiva: Apuntes sobre el Sistema Interamericano Temas de Derecho Público, Bogotá, Universidad Externado de Colombia.

Crawford, J. (2004). Los artículos de la Comisión de Derecho Internacional sobre la responsabilidad Internacional del Estado, ediciones Dykinson, S.L., Madrid.

Fix Zamudio, H. (1982). La protección procesal de los derechos humanos ante las jurisdicciones nacionales, Editorial Civitas.

Henao Pérez, J.C. (2005). El Daño, análisis comparativo de la responsabilidad extracontractual del Estado en derecho colombiano y francés, ediciones Universidad Externado de Colombia, quinta reimpresión, Bogotá.

Ministerio de Relaciones Exteriores y Culto. (1999). Los Derechos Humanos en Costa Rica. Costa Rica.

Lozano, V.A. (2009). Igualdad en el acceso al sistema interamericano de protección de los derechos humanos, en la obra colectiva: Apuntes sobre el Sistema 
Interamericano, Temas de Derecho Público, Bogotá, Universidad Externado de Colombia.

Pelaéz Gutiérrez, J.C. (2000). Reflexiones sobre los fundamentos de la jurisprudencia administrativa francesa y colombiana en materia de actos de terrorismo. Instituto de Estudios Constitucionales Carlos Restrepo Piedrahita, Bogotá.

\section{Documentos}

Convención Americana de Derechos Humanos.

Convención Americana para Prevenir y Sancionar la Tortura.

Corte Interamericana de Derechos Humanos:

Caso Caballero Delgado y Santa Vs. Colombia, sentencia de 8 de Diciembre de 1995.

Caso las Palmeras vs. Colombia, sentencia de 6 de diciembre de 2001.

Caso 19 Comerciantes vs. Colombia, sentencia de 5 de julio de 2004.

Caso Gutiérrez Soler vs. Colombia, sentencia de 12 de septiembre de 2005.

Caso de la Masacre de Mapiripán vs. Colombia, sentencia de 15 de septiembre de 2005.

Caso de la Masacre de Pueblo Bello vs. Colombia, sentencia de 31 de enero de 2006.

Caso de las Masacres de Ituango vs. Colombia, Sentencia de 1 de julio de 2006.

Caso de la Masacre de la Rochela vs. Colombia, sentencia de 11 de mayo de 2007.

Caso Escué Zapata vs. Colombia, sentencia de 4 de julio de 2007.

Caso Valle Jaramillo y otros vs. Colombia, sentencia de 27 de noviembre de 2008.

Caso Zambrano Vélez y otros vs. Ecuador sentencia de 4 de julio de 2007.

Opinión consultiva OC-8/87 de 30 de enero de 1987.

Opinión consultiva OC- 9/87 de 6 de Octubre de 1987.

Página Web de la Corte Interamericana de Derechos Humanos Recuperada de http://www.corteidh.or.cr, 17 de febrero de 2009. 